\title{
Wait times for gastroenterology consultation in Canada: The patients' perspective
}

\author{
WG Paterson $M D^{1}$, AN Barkun $\mathrm{MD}^{2}$, WM Hopman $M A^{1}$, DJ Leddin $M D^{3}, \mathrm{P}^{2}$ Paré $\mathrm{MD}^{4}$, DM Petrunia $\mathrm{MD}^{5}$, \\ MJ Sewitch $\mathrm{PhD}^{2}$, C Switzer MD ${ }^{6}$, S Veldhuyzen van Zanten $\mathrm{MD}^{3,6}$
}

\begin{abstract}
WG Paterson, AN Barkun, WM Hopman, et al. Wait times for gastroenterology consultation in Canada: The patients' perspective. Can J Gastroenterol 2010;24(1):28-32.
\end{abstract}

Long wait times for health care have become a significant issue in Canada. As part of the Canadian Association of Gastroenterology's Human Resource initiative, a questionnaire was developed to survey patients regarding wait times for initial gastroenterology consultation and its impact. A total of 916 patients in six cities from across Canada completed the questionnaire at the time of initial consultation. Selfreported wait times varied widely, with $26.8 \%$ of respondents reporting waiting less than two weeks, $52.4 \%$ less than one month, $77.1 \%$ less than three months, $12.5 \%$ reported waiting longer than six months and $3.6 \%$ longer than one year. One-third of patients believed their wait time was too long, with $9 \%$ rating their wait time as 'far too long'; $96.4 \%$ believed that maximal wait time should be less than three months, $78.9 \%$ believed it should be less than one month and $40.3 \%$ believed it should be less than two weeks. Of those working or attending school, 22.6\% reported missing at least one day of work or school because of their symptoms in the month before their appointment, and $9.0 \%$ reported missing five or more days in the preceding month. A total of $20.2 \%$ of respondents reported being very worried about having a serious disease (ie, scored 6 or higher on 7-point Likert scale), and $17.6 \%$ and $14.8 \%$, respectively, reported that their symptoms caused major impairment of social functioning and with the activities of daily living. These data suggest that a significant proportion of Canadians with digestive problems are not satisfied with their wait time for gastroenterology consultation. Furthermore, while awaiting consultation, many patients experience an impaired quality of life because of their gastrointestinal symptoms.

Key Words: Patient survey; Quality of life; Wait times

$\mathrm{L}$ ong wait times for access to health care continue to be a major issue in Canada $(1,2)$. Indeed, both federal and provincial governments have recently targeted new funding to improve wait times in selected areas (3). The Canadian Association of Gastroenterology (CAG) has been concerned about access to digestive health care for several years. To address this issue, a three-pronged initiative was commenced in 2004 that included a process to document current wait times $(4,5)$ and the number of practicing digestive diseases specialists (6), and to establish target wait times for gastroenterological assessment, including consultation and endoscopic procedures (7). A CAG ad hoc committee charged with developing the process to establish target wait times concluded that to accomplish this effectively, information regarding the patient's perspective of current wait times was required. Therefore, the current study was undertaken to survey a large number of patients from centres across Canada regarding their perceptions of current wait times and the impact of wait time on quality of life.

\section{Les temps d'attente pour obtenir une consultation en gastroentérologie au Canada : Le point de vue du patient}

Les longs temps d'attente pour obtenir des soins de santé sont devenus un problème marqué au Canada. Dans le cadre du projet des ressources humaines de l'Association canadienne de gastroentérologie, les auteurs ont préparé un questionnaire afin de sonder les patients au sujet des temps d'attente afin d'obtenir une première consultation en gastroentérologie et de constater leurs répercussions. Au total, 916 patients de six villes du Canada ont rempli le questionnaire lors de leur première consultation. Les temps d'attente autodéclarés variaient considérablement, 26,8 \% des répondants déclarant une attente inférieure à deux semaines, $52,4 \%$, à un mois et $77,1 \%$, à moins de trois mois, ainsi que $12,5 \%$ une attente de plus de six mois et 3,6\%, de plus d'un an. Le tiers des patients trouvaient leur attente trop longue, $9 \%$ qualifiant leur attente de « beaucoup trop longue ». En fait, 96,4 \% des patients trouvaient que l'attente maximale devrait être inférieure à trois mois, $78,9 \%$, inférieure à un mois et $40,3 \%$, inférieure à deux semaines. Chez les personnes qui travaillaient ou étaient aux études, 22,6\% ont déclaré avoir raté au moins une journée de travail ou d'école en raison de leurs symptômes le mois précédant leur rendez-vous, et 9,0 \% ont déclaré en avoir raté au moins cinq journées au cours de cette période. Au total, 20,2 \% des répondants ont déclaré craindre énormément d'être atteints d'une grave maladie (ils ont obtenu un résultat de 6 ou plus sur l'échelle de Likert de 7 points), et $17,6 \%$ et $14,8 \%$, respectivement, ont déclaré que leurs symptômes nuisaient beaucoup à leur fonctionnement social et aux activités de leur vie quotidienne. Ces données laissent supposer qu'une forte proportion de Canadiens ayant des troubles digestifs ne sont pas satisfaits du temps d'attente avant d'obtenir une consultation en gastroentérologie. De plus, en attendant leur consultation, bon nombre d'entre eux voient leur qualité de vie diminuer en raison de leurs symptômes gastro-intestinaux.

\section{METHODS}

New patients attending outpatient clinics for gastroenterological consultation at six Canadian centres (Halifax, Nova Scotia; Quebec City and Montreal, Quebec; Kingston, Ontario; Edmonton, Alberta; and Victoria, British Columbia) were approached by clerical or nursing staff about participating in the study when they registered for their clinic visit. If they agreed to participate, they were given a letter introducing the study and signed a consent form before being administered a questionnaire (Appendix A). Key components of the questionnaire included the reason they were referred to a specialist, the length of their wait time, their perception of the appropriateness of the wait time, their estimation of what a maximally acceptable wait time should be, and the effect of wait time on their productivity and quality of life. Age, sex and postal code data were also collected. The questionnaire was available in French for francophone patients. The study was approved by either the hospital or university research ethics board of each site. There was no tracking of compliance

${ }^{1}$ Queen's University, Kingston, Ontario; ${ }^{2}$ McGill University, Montreal, Quebec; ${ }^{3}$ Dalhousie University, Halifax, Nova Scotia; ${ }^{4}$ Université Laval,

Quebec City, Quebec; ${ }^{5}$ Victoria General Hospital, Victoria, British Columbia; ${ }^{6}$ University of Alberta, Edmonton, Alberta

Correspondence: Dr WG Paterson, Division of Gastroenterology, Hotel Dieu Hospital, 166 Brock Street, Kingston, Ontario K7L 5G2.

Telephone 613-544-3400 ext 3376, fax 613-544-3114, e-mail patersow@hdh.kari.net

Received for publication December 30, 2008. Accepted March 24, 2009 
TABLE 1

Self-reported reasons for referral

\begin{tabular}{lccc}
\hline Reason for referral & Patients, $\mathbf{n}(\%)$ & $\begin{array}{c}\text { Wait time category, median } \\
\text { (interquartile range)* }\end{array}$ & Wait time category, mean \pm SD* \\
\hline Screening & $108(11.8)$ & $3(2-5)$ & $3.4 \pm 1.6$ \\
Rectal bleeding & $43(4.7)$ & $2(1-3)$ & $2.2 \pm 1.3$ \\
Dyspepsia & $158(17.2)$ & $2(2-4)$ & $2.7 \pm 1.4$ \\
Iron-deficient anemia & $17(1.9)$ & $2(1-3)$ & $2.3 \pm 1.2$ \\
Bowel dysfunction & $68(7.4)$ & $3(1-4)$ & $2.8 \pm 1.5$ \\
Inflammatory bowel disease & $68(7.4)$ & $3(2-3)$ & $2.5 \pm 1.1$ \\
Abdominal pain & $74(8.1)$ & $2(1-3)$ & $2.2 \pm 1.2$ \\
Other & $279(30.5)$ & $2(1-3)$ & $2.5 \pm 1.3$ \\
Not stated & $101(11)$ & $2(1-3)$ & $2.4 \pm 1.3$ \\
\hline
\end{tabular}

*Score is based on a scale of $1=$ less than two weeks, $2=$ less than one month, $3=$ less than three months, $4=$ less than six months, $5=$ less than one year, $6=$ more than one year. Although the data are ordinal, mean values are also presented due to the homogeneity of the median values. Between-reason differences in wait time category were statistically significant $(P<0.001$ [Kruskal-Wallis test])

with the distribution of the questionnaire or the questionnaire completion rate, although clerical staff reported that very few patients refused to complete the questionnaire when asked.

Research personnel not involved with the patient's care entered the data for statistical analysis into an Excel (Microsoft Corp, USA) spreadsheet that was imported into SPSS version 16.0 (SPSS Inc, USA) for Windows (Microsoft Corp, USA). Following descriptive analyses, $\chi^{2}$ tests were used to compare the distributions for categorical wait time variables according to reason for referral. Mann-Whitney $U$ nonparametric tests and $t$ tests were used to compare wait time responses by patients with and without a serious problem. One-way ANOVA and Kruskal-Wallis nonparametric tests were used to compare wait time responses according to centre.

\section{Patient population}

\section{RESULTS}

A total of 916 patients completed questionnaires at the six centres between November 2004 and February 2005. The number of questionnaires completed per centre ranged from 37 to 363 . Although all centres were affiliated with academic institutions, the vast majority of the outpatient practice at each centre consisted of patients referred from primary care physicians. Fifty-nine per cent of the respondents were women and $26 \%$ were francophone. An analysis of postal codes indicated that $88 \%$ resided in an urban setting and $12 \%$ were from a rural community. The selfreported reasons for referral are summarized in Table 1.

\section{Wait times}

Self-reported wait times varied widely, ranging from a few days to more than two years. Figure 1 depicts the cumulative percentage of self-reported wait times up to one year compared with the maximal acceptable wait times recommended by the patients. Approximately one-third of patients believed that their wait time was too long, which included $9 \%$ who rated their wait time in the 'far too long' category. Of note, $96 \%$ of the population believed that the maximal acceptable wait time should be less than three months, yet $23 \%$ of the sample reported waiting more than three months for their initial consultation.

Impact on work and/or school absenteeism, and quality of life Approximately $23 \%$ of respondents reported missing at least

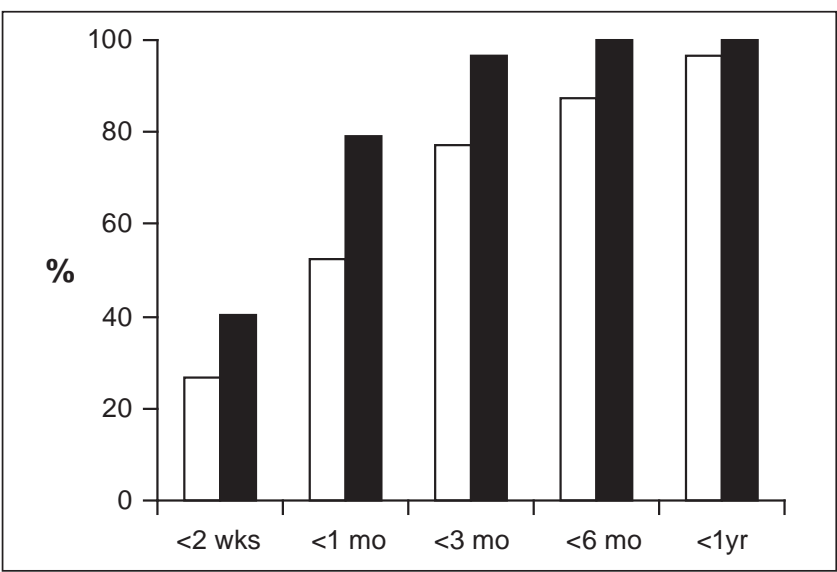

Figure 1) Self-reported wait times (white bars represent the cumulative percentage of patients seen within the stated time period) compared with maximally acceptable wait times (black bars represent percentage of patients reporting that time period as maximally acceptable). Whereas $79 \%$ of surveyed patients believed that the maximal acceptable wait time should be less than one month, slightly more than one-half reported being seen within this time frame. mo Month(s); wks Weeks; yr Year

one day of work or school in the preceding month because of their gastrointestinal symptoms. Nearly 10\% reported missing five or more days of work or school during that period. In addition, $20 \%$ of patients scored 6 or higher on a 7 -point Likert scale with regard to the degree of worry that their symptoms were related to serious disease. Eighteen per cent and $14.8 \%$ of patients scored 6 or higher on a 7-point Likert scale, indicating that their symptoms interfered with social functioning and activities of daily living, respectively.

\section{Relationship between reported wait time and reason for referral}

The self-reported wait time varied depending on the reason for referral (Table 1). For example, as depicted in Figure 2, the cumulative percentage of patients seen for rectal bleeding was significantly higher at all time intervals compared with individuals referred for screening procedures, suggesting that referrals were being triaged for relative urgency (Pearson $\chi^{2}$ test 26.0; $\mathrm{P}<0.001$ for the percentage seen at each time interval). 


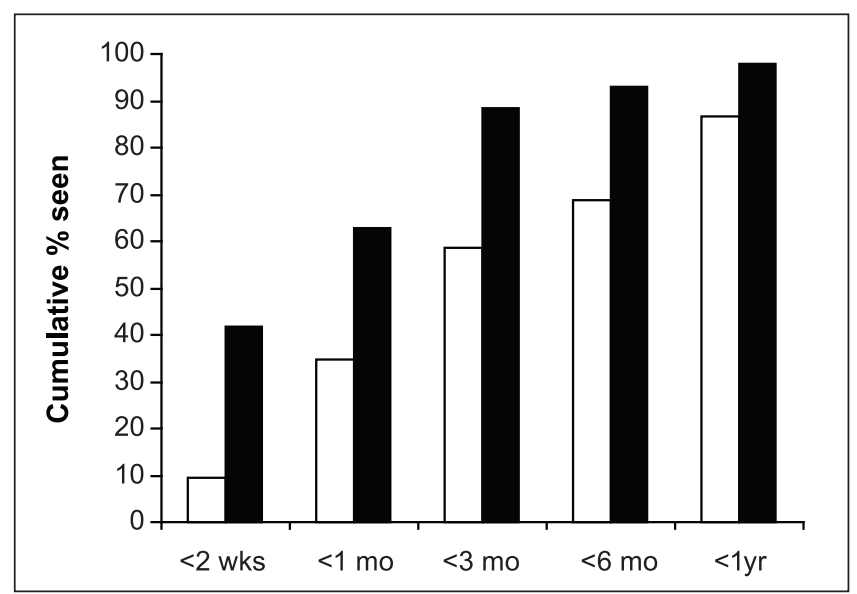

Figure 2) Self-reported wait time varied depending on the reason for referral, with the cumulative percentage seen being significantly higher at all time intervals for those referred for rectal bleeding (black bars) versus screening (white bars) (Pearson $\chi^{2}$ test 26.0, $P<0.001$ for the per cent seen at each time interval). mo Month(s); wks Weeks; yr Year

\section{Variations among centres}

There were marked variations in wait time responses among the six sites. For instance, the proportion of patients who reported being seen in less than two weeks varied from $5.4 \%$ to $41.4 \%$, and the proportion of patients waiting longer than six months varied from $0.7 \%$ to 29.2\%. As depicted in Figure 3, this was partly related to variations in reasons for referral more specifically, that overall wait time duration at the different centres varied with the proportion of surveyed patients being referred for screening procedures. One-way ANOVA revealed that the between-centre differences were statistically significant $(\mathrm{F}=16.8 ; \mathrm{P}<0.001)$.

\section{DISCUSSION}

The objective of the current study was to obtain Canada-wide data on the patient perspective concerning wait times for outpatient gastroenterological consultation to inform decisions regarding the establishment of wait time targets. The data obtained by the present survey are quite unique. Although patient perception of wait time and its impact have been surveyed in patient groups waiting for elective surgery $(8-11)$, the present study was the first to focus on the wait time for consultation in undiagnosed conditions, as well as the first to target gastroenterology patients. In addition to providing important insight into patients' perceptions of what appropriate wait times should be, the survey results suggest that current wait times are having an adverse effect on patients in need of specialist care for digestive disorders.

Although not designed to accurately measure wait times because of the potential information bias inherent in selfreporting, the wait times reported in the present study are consistent with recently published data from the Practice Audit in Gastroenterology (PAGE) IV program (4,5). Furthermore, preliminary results from the Canada-wide Survey of Access to GastroEnterology (SAGE) conducted in late 2008, suggest that wait times for gastrointestinal care have either remained stable or increased in Canada in the past five years (D Leddin, unpublished data). Approximately one-half of the patients in the current survey reported being seen by a

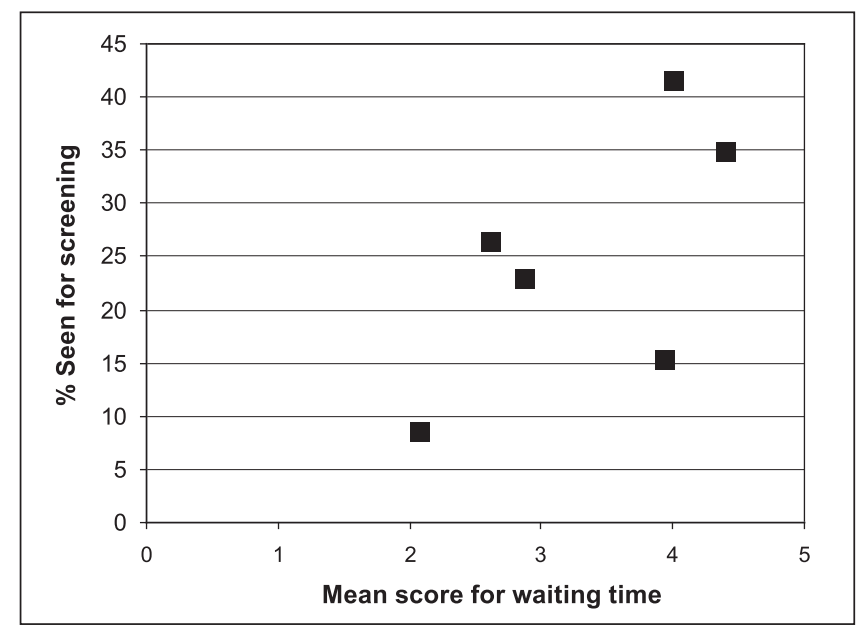

Figure 3) Variability in patient self-reported wait time varied among centres, related in part to differences in the referral population. Each dot on the above graph indicates a different centre. Note that wait time varied directly with the proportion of patients who were referred for screening and completed the questionnaire (one-way ANOVA revealed statistical significance among centres $[F=16.8, P<0.001])$

gastroenterologist within one month of being referred by their primary care physician. At first glance, this may seem reasonable but it must be remembered that this includes a significant number of patients with relatively urgent conditions such as rectal bleeding, iron deficiency anemia and suspicion of inflammatory bowel disease (Table 1). Furthermore, most of these patients would have had to wait additional time for a subsequently scheduled endoscopic procedure (12); therefore, their true wait time for appropriate gastroenterological evaluation would be longer. It is noteworthy that $12.5 \%$ of patients reported waiting longer than six months for their outpatient consultation.

What patients believed to be a maximally acceptable wait time varied widely, which, at least in part, likely reflected the nature of the condition that led to their gastroenterology referral. However, the vast majority of patients (96\%) believed that the maximally acceptable wait time should be no longer than three months, although only $77 \%$ reported being seen within this time frame. Accordingly, approximately one-third of patients reported their wait time to be too long, with $9 \%$ rating their wait time as 'far too long'. It is possible that this actually underestimates the degree of dissatisfaction, in that patients were surveyed on the day they were being seen by the gastroenterologist. A recent study regarding patient satisfaction with endoscopy services found that there was a greater degree of patient satisfaction when the survey was performed on-site rather than when mailed back at a later date (13). The results may have been quite different if patients had been surveyed subsequent to their visit, or perhaps more so at the time of initial referral when, in many instances, they were anticipating a wait of several months before being seen. It is also possible that Canadian patients have been conditioned to accept long wait times because access to medical services and wait times have been a frequent topic in the media. In the United States and some other countries, where wait times do not appear to be a concern, it is unlikely that patients would consider a threemonth wait to see a gastroenterologist acceptable. 
Another important observation in the present study was that a substantial number of patients reported absenteeism and impairment in quality of life as a result of their gastrointestinal condition while waiting for consultation. This is reflected by the fact that more than $20 \%$ reported missing at least one day of school or work in the preceding month as a result of their digestive problem, and 9\% reported missing five or more days. These findings suggest, that in addition to patients experiencing unnecessary physical and emotional distress while waiting, there is an unmeasured financial cost related to delayed access. A recent report (14) highlighted the enormous costs inherent to long wait times because of lost productivity.

A striking finding was the strong correlation observed between average self-reported wait times in a centre and the proportion of patients completing the questionnaire who were referred for screening procedures. Although this analysis was based on 108 patients (11.8\% of all referrals), the results were highly significant and homogeneous. It is uncertain whether these longer average wait times were due entirely to including a greater proportion of screening patients in the survey at a given centre or, whether centres taking on a greater screening workload were compromised in their ability to accommodate other referrals in a timely fashion.

The current study had several limitations. In addition to the potential information bias mentioned above, selection bias may have also occurred because compliance with survey completion was not systematically documented and strict processes were not in place to ensure that consecutive patients were enrolled. However, clerical and nursing staff were asked to offer the survey to all patients attending the outpatient gastroenterology clinic for a new patient consultation, and it is unlikely that they were systematically selective in their distribution of questionnaires. Although it remains possible that patients with more or less concern regarding wait times were more likely to complete the survey, our nursing staff reported that very few patients refused to complete the survey when it was offered.

There was significant variability in the number of patients participating in the survey at the different centres, although all but one centre recruited more than 100 patients. This discrepancy relates largely to the number of individual gastroenterologists enrolling patients at the different centres, and the fact that some centres started administering the questionnaires later than others and, thus, had less time to accrue patients before the imposed deadline for completion of the study. More significant than the numbers enrolled is the marked difference in the type of patient being seen in the outpatient departments of the different centres and varying practices, such as openaccess endoscopy. However, we do not believe this detracted significantly from the primary purpose of the study, which was to get a sampling of perspectives on wait times from a large cohort of patients from across Canada to provide the required patient input in the process of establishing wait time targets for specialist digestive health care (7).

\section{SUMMARY}

The findings of the current study are consistent with other recently published data $(4,5,7,12)$ suggesting that timely access to specialized digestive health care is suboptimal in Canada. Furthermore, a substantial number of patients are dissatisfied with their wait time for consultation with a gastroenterologist and

\section{APPENDIX A: Questionnaire}

1) What is the main reason why you have been referred to a specialist?

2) How long have you been waiting since you were referred to a specialist?

$\begin{array}{ll}\text { Less than } 2 \text { weeks } & \text { Less than } 6 \text { months } \\ \text { Less than } 1 \text { month } & \text { Between } 6 \text { months and } 1 \text { year } \\ \text { Less than } 3 \text { months } & \text { More than } 1 \text { year }\end{array}$

3) Approximately how long did you have your problem before you first saw a doctor?

Less than 2 weeks Less than 6 months

Less than 1 month Between 6 months and 1 year

Less than 3 months More than 1 year

4) Did you have a previous appointment that was missed or had to be rescheduled?

No Yes

5) Do you think the time you had to wait for this appointment was:

$\begin{array}{ll}\text { Far too short } & \text { Somewhat too long } \\ \text { Somewhat too short } & \text { Far too long }\end{array}$

About right

6) What do you think the maximum wait time for this appointment should have been?

No more than a few days Less than 3 months

Less than 2 weeks Less than 6 months

Less than 1 month

7) Has your doctor told you what he/she thinks your diagnosis is?

No Yes

8) Has your doctor told you whether or not he/she thinks you have a serious problem?

No Yes

9) While waiting for this appointment, have you had ongoing symptoms that have caused you to miss work or school?

No

Less than 5 days per month Totally unable to work/go to schoo

More than 15 days per month

Between 5 to 15 days per month Not applicable (not working/going to school)

10) While you have been waiting for this appointment, how worried have you been about a serious undiagnosed disease of your digestive system? (Circle the number that corresponds best to how worried you have been; the higher the number means greater worry)

\begin{tabular}{lllllll} 
Not at all & & & & \multicolumn{2}{c}{ Very much so } \\
\hline 1 & 2 & 3 & 4 & 5 & 6 & 7
\end{tabular}

11) While waiting for this appointment, have you had ongoing symptoms that have interfered with your ability to participate in your usual social or recreational activities? (Circle the number that corresponds best with how much your symptoms have interfered with your social or recreational activities; the higher the number means greater interference) Not at all

$\begin{array}{llllllr}1 & 2 & 3 & 4 & 5 & 6 & 7\end{array}$

12) While waiting for this appointment, have you had ongoing symptoms that have interfered with your ability to carry out normal activities of daily living (e.g. preparing and eating meals, household tasks, sleeping, personal hygiene, etc) (Circle the number that corresponds best with how much your symptoms have interfered with your ability to carry out normal activities; the higher the number means greater interference) Not at all Very much so
1
2
3
4
5
6
7

report an impaired quality of life and decreased work productivity due to their digestive illness while waiting for specialist care.

ACKNOWLEDGEMENT: The patient survey was supported by funding from the Canadian Association of Gastroenterology. 


\section{REFERENCES}

1. Statistics Canada. Access to Health Care Services in Canada: January to June 2005. <http://www.statcan.gc.ca/cgi-bin/af-fdr. cgi?l=eng\&loc $=$ http://www.statcan.gc.ca/pub/82-575-x/82-575x2006002-eng.pdf\&t $=$ Access $\% 20$ to\%20Health\%20Care\%20

Services\%20in\%20Canada> (Version current at Decemebr 1, 2009).

2. Waiting Your Turn: Hospital Waiting Lists in Canada, 15th Edition Nadeem Esmail, Michael Walker; Fraser Institute: October 2005.

3. Health Canada. Health Care System. A 10-year plan to strengthen health care. September 16, 2004. <http://www.hc-sc.gc.ca/hcs-sss/ delivery-prestation/fptcollab/2004-fmm-rpm/nr-cp_9_16_2_e.html>. (Version current at November 30, 2009).

4. Armstrong D, Barkun AN, Chen Y, et al. Access to specialist gastroenterology care in Canada: The Practice Audit in Gastroenterology (PAGE) Wait Times Program.

Can J Gastroenterol 2008;22:155-60.

5. Leddin D, Armstrong D, Barkun AN, et al. Access to specialist gastroenterology care in Canada: Comparison of wait times and consensus targets. Can J Gastroenterol 2008;22:161-7.

6. Moayyedi P, Tepper J, Hilsden R, Rabeneck L. International comparisons of manpower in gastroenterology. Am J Gastroenterol 2007;102:478-81.

7. Paterson WG, Depew WT, Paré P, et al. Canadian consensus on medically acceptable wait time for digestive health care. Can J Gastroenterol 2006;20:411-23.
8. Janzen JA, Hadjistavropoulos HD. Examination of negative affective responses to waiting for sugery. Can J Nurs Res 2008;40:72-91.

9. Llewellyn-Thomas H, Thiel E, Paterson M, Naylor D. In the queue for coronary artery bypass grafting: Patients' perception of risk and maximal acceptable wait time. J Health Serv Res Policy 1999;4:65-72.

10. Dunn E, Black C, Alonso J, Noregaard JC, Anderson GF. Patients' acceptance of waiting for cataract surgery: What makes a wait too long? Soc Sci Med 1997;44:1603-10.

11. Oudhoff JP, Timmermans DRM, Knol DL, Bijnen AB, van der Wal G. Waiting for elective general surgery: Impact on health-related quality of life and psychosocial consequences. BMC Public Health 2007;7:164.

12. Yu D, Hopman WM, Paterson WG. Wait time for endoscopic evaluation at a Canadian tertiary care centre: Comparison with Canadian Association of Gastroenterology targets. Can J Gastroenterol 2008;22:621-6.

13. Lin OS, Schembre DB, Ayub K, et al. Patient satisfaction scores for endoscopic procedures: Impact of a survey collection method. Gastrointest Endosc 2007;65:775-81.

14. The Centre for Spatial Economics (prepared for the Canadian Medical Association). The economic cost of wait times in Canada. 2008. <http://www.waittimealliance.ca/> (Version current at October 30, 2009). 


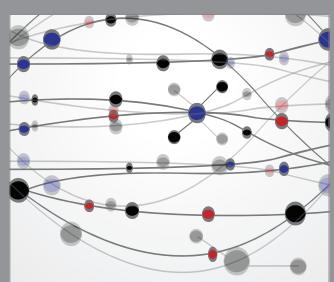

The Scientific World Journal
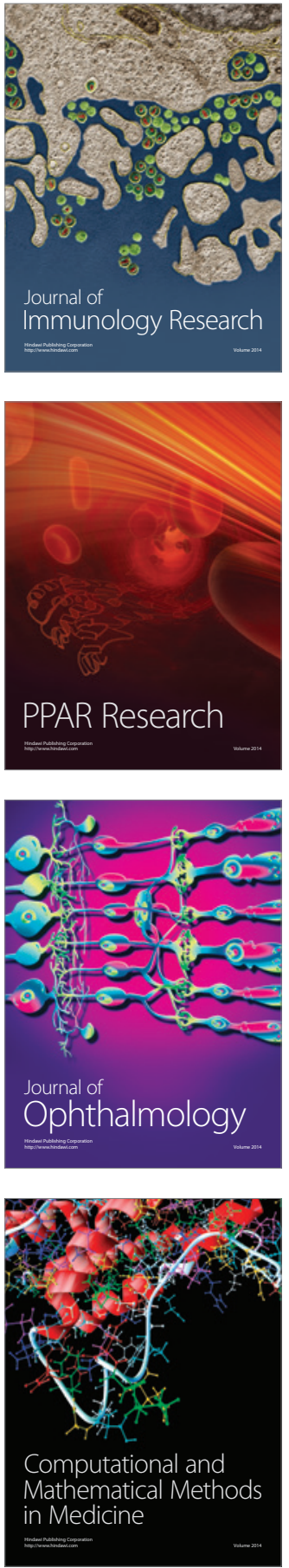

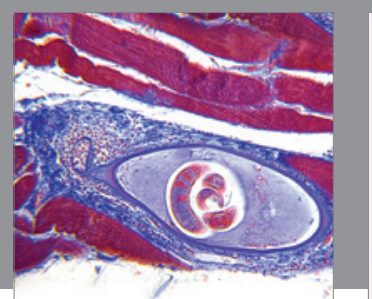

Gastroenterology Research and Practice

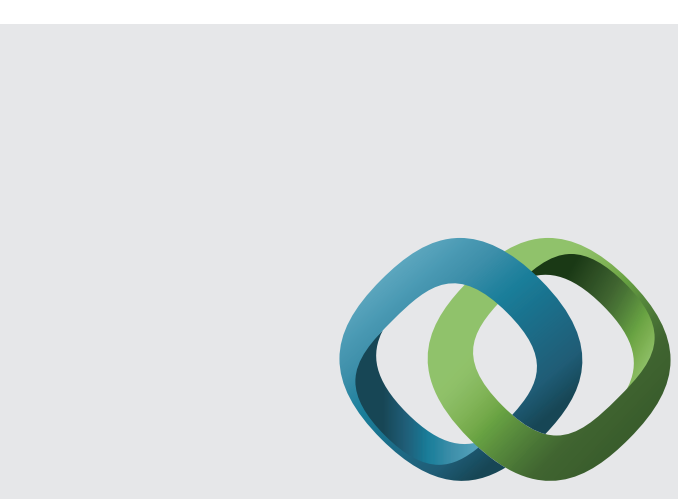

\section{Hindawi}

Submit your manuscripts at

http://www.hindawi.com
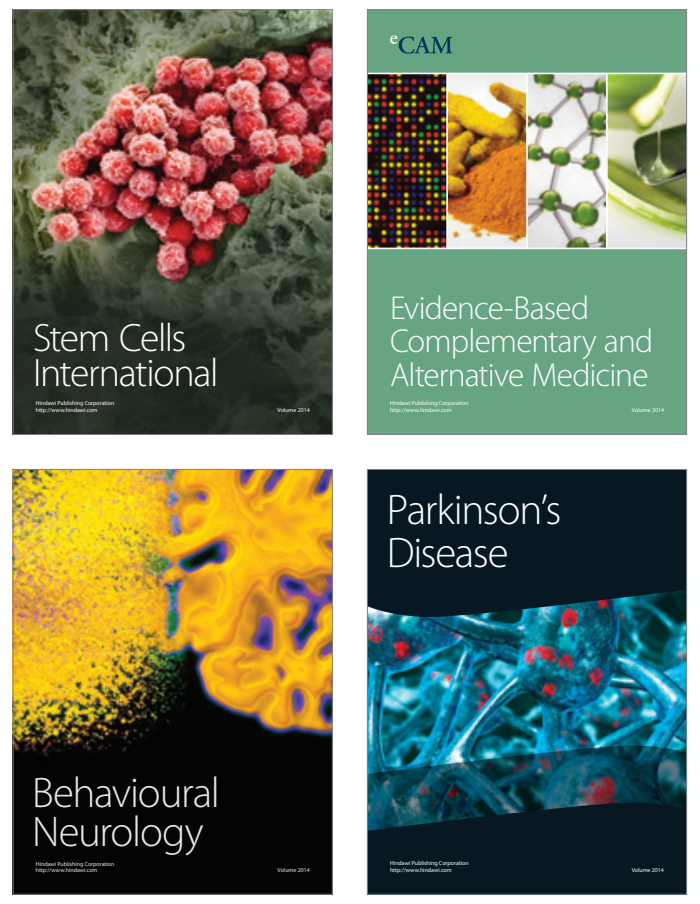
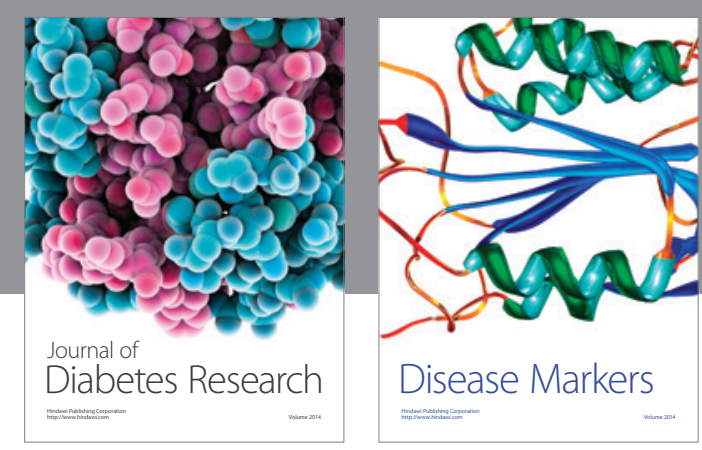

Disease Markers
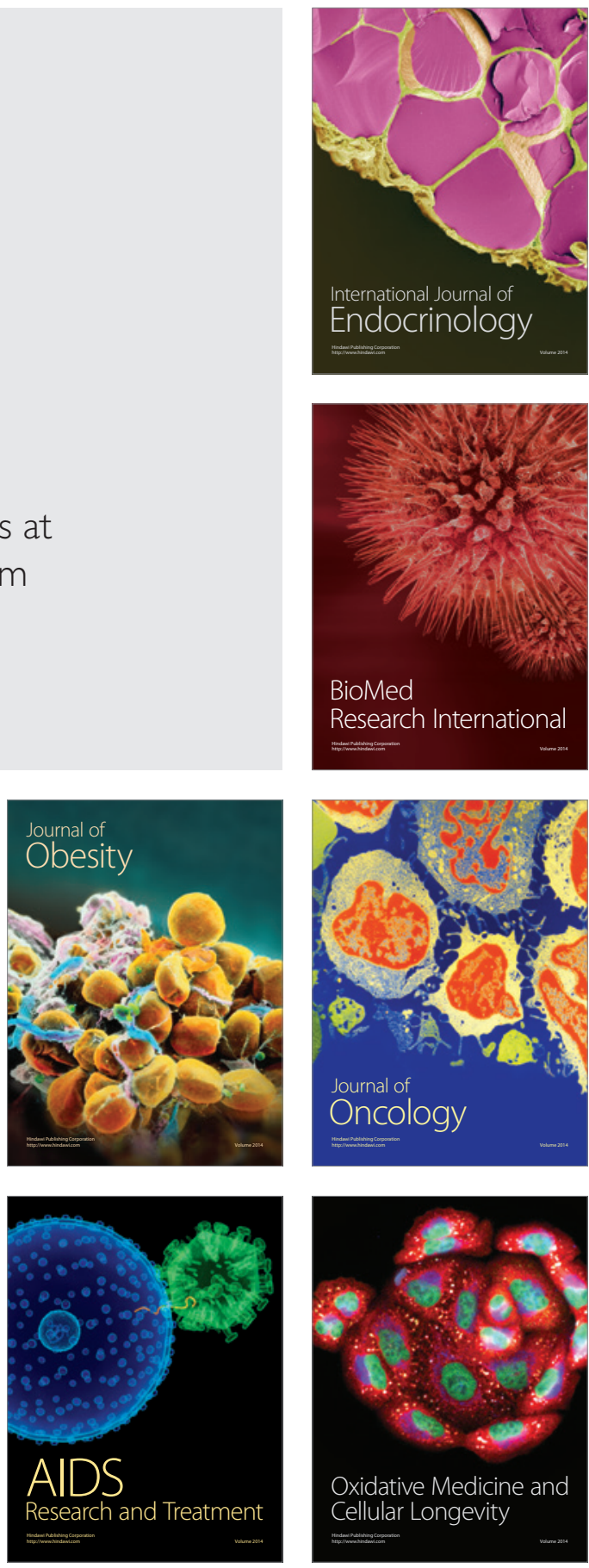